\title{
Controlled Low Strength Materials (CLSM), Reported by ACI Committee 229
}

by

N. Rajendran

Westinghouse Savannah River Company

Savannah River Site

Aiken, South Carolina 29808

\section{DOE Contract No. DE-AC09-96SR18500}

\section{DISTAIBUTION OF THIS DOCUMENT IS UNLIMITED}

This paper was prepared in connection with work done under the above contract number with the U.S.

Department of Energy. By acceptance of this paper, the publisher and/or recipient acknowledges the U.S. Government's right to retain a nonexclusive, royalty-free license in and to any copyright covering this paper, along with the right to reproduce and to authorize others to reproduce all or part of the copyrighted paper. 


\section{DISCLAIMER}

This report was prepared as an account of work sponsored by an agency of the United States Government. Neither the United States Government nor any agency thereof, nor any of their employees, makes any warranty, express or implied, or assumes any legal liability or. responsibility for the accuracy, completeness, or usefulness of any information, apparatus, product, or process disclosed, or represents that its use would not infringe privately owned rights. Reference herein to any specific commercial product, process, or service by trade name, trademark, manufacturer, or otherwise does not necessarily constitute or imply its endorsement, recommendation, or favoring by the United States Government or any agency thereof. . The views and opinions of authors expressed herein do not necessarily state or reflect those of the United States Govemment or any agency thereof.

This report has been reproduced directly from the best available copy.

Available to DOE and DOE contractors from the Office of Scientific and Technical Information, P.O. Box 62, Oak Ridge, TN 37831; prices available from (615) 57.6-8401.

Available to the public from the National Technical.Information Service, U.S. Department of Commerce, 5285 Port Royal Road, Springfield, VA 22161. 


\section{DISCLAMMER}

Portions of this document may be illegible in electronic image products. Images are produced from the best available original document. 


\title{
Controlled Low Strength Materials (CLSM)
}

\author{
Reported by ACI Committeè 229
}

Wayne S. Adaska

Chairman

Joseph A. Amon Richard L. Boone William E. Brewer Theresa J. Casias Christopher Crouch Jose E. Fernandez

Controlled low-strength material (CLSM) is a self-compacted, cementitious material used primarily as a backfill in lieu of compacted fill. Many terms are currently used to describe this material including flowable till, unshrink-able fill, controlled density fill, flowable mortar, ffowable fly ash, fly ash slurry, plastic soil-cement, soil-cement slurry, $K$-Krete* and other various names. This report contains information on applications, material proper-ties, mix proportioning, construction and quality-control procedures. This report's intent is to provide basic information on CLSM technology, with emphasis on CLSM material characteristics and advantages over conven-tional compacted fill.

Keywords: aggregates, backfill, compacted fill, controlled density fill, controlled low-strength material, flowable fill, flowable mortar, fly ash,

foundation stabilization, low density material, pipe bedding, plastic soil-cement, preformed foam, soil-cement slurry, trench backfill, unshrinkable fill, void filling.

\section{CONTENTS}

Chapter 1 Introduction, p. 229R-2

Chapter 2 Applications, p. 229R-2

2.1_-General

2.3 Structural fills

2.4 Insulating and isolation fills

2.5 Pavement bases

2.6 Conduit bedding

2.7 Erosion control

$2.8^{-}$Void filling

2.9 Nuclear facilities

ACl Committee Reports, Guides, Standard Practices, and Commentaries are intended for guidance in designing, plan-ning, executing, or inspecting construction and in preparing specifications. References to these documents shall not be made in the Project Documents. If items found in these documents are desired to be part of the Project Docu-ments, they should be phrased in mandatory language and incorporated into the Project Documents.
Ronald L. Larsen

Leo A. Legatski

Donald E. Milks

Daniel J. Morrell

Bruce W. Ramme

J. David Robson

Chapter 3 Materials, p. 229R-5

3.1 General

3.2 Portland cement

3.3 Fly ash

3.4 Chemical admixtures

3.5 Other additives

3.6 Water

3. Aggregates $^{-}$

3.8 Non-standard material

3.9 Pond ash/Basin ash

z.+Pf actitives

Chapter 4_Properties, p. 229R-6

4.1 Intróduction

4.2 Plastic properties

$4.3^{-}$In-service properties

Chapter 5 Mix proportioning, p. 229R-8

Chapter 6 Construction. p. 229R-8

6.1 General

6.2 Mixing

6.3_Transporting

6.4_Placing

Chapter 7_Quality control, p. 229R-10

7.1 General

7.2 Consistency and unit weight

7.3_Strength tests

Chapter 8 Low density CLSM using preformed foam, p. $2 \overline{2} 9 \mathrm{R}-10$

8.1 General

8.2_Applications

ACl 229R-94 became effective October 1, 1994

Copyright (C) 1994, American Concrete Institute.

All rights reserved including rights of reproduction and use in any form or by any means, including the making of copies by any photo process, or by any elec-tronic or mechanical device, printed, written, or oral, or recording for sound of visual reproduction for use in any knowledge or retrieval system or device, unless permission in writing is obtained from the copyright proprietors.

*Krete is a trade name for this type of material. 
- Ready available Using locally available materials, ready mixed concrete suppliers can produce CLSM to meet most project specifications.

- Easy to deliver Truck mixers can deliver specified quantities of CLSM to the jobsite whenever the material is needed.

- Easy to place Depending on the type and location of void to be filled, CLSM can be placed by chute, conveyor, pump, or bucket. Because CLSM is self-leveling, it needs little or no spreading or compacting. This speeds construction and reduces labor requirements.

- Versatile CLSM mix designs can be adjusted to meet specific fill requirements. Mixes can be adjusted to improve flowability. Add more cement or fly ash to increase strength. Admixtures can be added to adjust setting times and other performance characteristics. Adding foaming agents to CLSM produces a lightweight, insulating fill.

- Strong and durable_Load-carrying capacities of CLSM typically are higher than those of compacted soil or granular fill. CLSM also is less permeable, thus more resistant to erosion. For use as a permanent structural fill, CLSM can be designed to achieve 28 day compressive strength as high as 1200 psi.

- Can be excavated CLSM having compressive strengths of 50 to 100 psi is easily excavated with conventional digging equipment, yet is strong enough for most backfilling needs.

- Requires less inspection_during placement, soil backfill must be tested after each lift for sufficient compaction. CLSM self-compacts consistently and does not need this extensive field testing.

8.3 Materials

8.4 Properties

8.5 Proportioning

8.6_Construction

Chapter 9 References, p. 229R-12

\section{CHAPTER 1 INTRODUCTION}

Controlled low-strength material (CLSM) is a selfcompacted, cementitious material used primarily as a - backfill in lieu of compacted fill. Several terms are currently used to describe this material including flowable fill, unshrinkable fill, controlled density fill, flowable mortar, plastic soil-cement, soil-cement slurry, K-Krete and other various names. Controlled low-strength mater-ials are defined by "Cement and Concrete Terminology $(\mathrm{ACl} 116 \mathrm{R})$ " as materials that result in a compressive strength of 1200 psi or less. Most current CLSM applica-tions require unconfined compressive strengths of 300 psi or less. This lower strength requirement is necessary to allow for future excavation of CLSM.

The term CLSM can be used to describe a family of mixtures for a variety of applications. For example the upper limit of 1200 psi allows use of this material for applications where future excavation is unlikely such as structural fill under buildings. Low density CLSM, as described in Chapter 8 of this report, describes a material with distinctive properties and mixing procedures. Future CLSM mixtures may be developed as anticorrosion fills, thermal fills and durable pavement bases.

Controlled low-strength material should not be considered as a type of low strength concrete, but rather a
- Allows fast return to traffic Because many CLSM's can be placed quickly and support traffic loads within several hours, downtime for pavement repairs is minimal.

- Will not settle CLSM does not form voids during placement and sill not settle or rut under loading. This advantage is especially significant if the backfill is to be covered by a pavement patch. Soil or granular fill, if not consolidated properly, may settle after a pavement patch is placed and forms cracks or dips in the road.

- Reduces excavation costs_CLSM allows narrower trenches because it eliminates having to widen trenches to accommodate compaction equipment.

- Improves worker safety Workers can place CLSM in a trench without entering the trench, reducing their exposure to possible caveins.

- Allows all-weather construction CLSM will displace any standing water left in a trench from rain or melting snow, reducing the need for dewatering pumps. To place CLSM in cold weather, heat the material using the same methods for heating ready-mixed concrete.

- Reduces equipment needs Unlike soil or granular backfill, CLSM can be placed without loaders, rollers, or tampers.

- Requires no storage Because ready-mixed concrete trucks deliver CLSM to the jobsite in the quantities needed, storing fill material on site is unnecessary. Also, there is no leftover fill to haul away.

- Makes use of a by-product Fly ash is a byproduct produced by power plants that burn coal to generate electricity. CLSM containing fly ash benefits the environment by making use of this industrial byproduct material.

self-compacted backfill material that is used in place of compacted till. Generally CLSM mixtures are not de-signed to resist freezing and thawing, abrasive or erosive forces, or aggressive chemicals. Non-standard materials may be used to produce CLSM as long as the materials have been tested and found to satisfy the intended appli-cation.

Also, CLSM should not be confused with compacted soil-cement. Soil cement, as defined by $\mathrm{ACl}$ Committee 230 on Soil-Cement, requires compaction and curing. CLSM typically requires no compaction (consolidation) or curing to achieve the desired strength. Long-term compressive strengths for compacted soil-cement often exceed the 1200 psi maximum limit established for CLSM.

Long-term compressive strengths of 50 to $300 \mathrm{psi}$ are very low when compared to concrete. However, in terms of allowable bearing pressure, which is a common cri-terion for measuring the capacity of a soil to support a load, 50 to 100 psi strength is equivalent to a well com-pacted fill.

Although CLSM generally costs more per cubic yard than most soil or granular backfill materials, its many advantages often result in lower in-place costs. In fact, for some applications, CLSM may be the only reasonable backfill method available. Table 1.1 lists a number of advantages to using CLSM.'

\section{CHAPTER 2 APPLICATIONS}

\subsection{General}

$\bar{A} s$ stated earlier, the primary application of CLSM is as a structural fill or backfill in lieu of compacted soil. Because CLSM needs no compaction and can be de- 
signed to be very fluid, it's ideal for use in tight or restricted-access areas where placing and compacting fill is difficult. If future excavation is anticipated, the maximum long term compressive strength should gener-ally not exceed $300 \mathrm{psi}$. The following applications are intended to present a range of uses for CLSM.

\subsection{Backfills}

CLSM can be readily placed into a trench, hole or other cavity (Fig. 1.1 and 1.2). Compaction is not required, hence the trench width or size of excavation may be reduced. Granular or site excavated backfill, even if compacted properly in the required layer thickness, may not achieve the uniformity of CLSM.

When backfilling against retaining walls, consideration should be given to the lateral pressures exerted on the wall by flowable CLSM. Where the lateral fluid pressure may be a concern, CLSM may be placed in layers with each layer allowed to harden prior to placing the next layer.

Following severe settlement problems of soil backfill in utility trenches, the city of Peoria, Illinois, in 1988 , tried CLSM as an alternate backfill material. The CLSM was placed in trenches up to $9 \mathrm{ft}$. deep. Although fluid at time of placement, the CLSM "hardened" to the extent that a person's weight could be supported within 2 to $3 \mathrm{hr}$. Very few shrinkage cracks were observed. Further tests were conducted on replacing the pavement patching in a 3 to 4 -hr time frame. In one test, a pavement patch was successfully placed over a sewer trench immediately after the trench was backfilled. As a result of these initial tests, the city of Peoria has changed its backfilling procedure to require the use of CLSM on all street openings. ${ }^{1}$

\subsection{Structural fills}

CLSM may be used for foundation support. Compres-sive strengths may vary from 100 to 1200 psi depending upon application. In the case of weak soils, it can dis-tribute the structure's load over a greater area. For uneven or nonuniform subgrades under foundation foot-ings and slabs, CLSM can provide a uniform and level surface. Compressive strengths will vary depending upon project requirements. Because of its strength, CLSM may reduce the required thickness or strength requirements of the slab. Near Boone, lowa, 2800 cubic yards of CLSM was used to provide proper bearing capacity for the footing of a grain elevator that was to be built on load bearing soil?

\subsection{Insulating and isolation fills}

Low density CLSM material is generally used for these applications. Chapter 8 addresses low density CLSM material using preformed foam.

\subsection{Pavement bases} sub-

CLSM mixtures may be used for pavement bases,

Fig. 1.1_Using CLSM to backfill adjacent to a building foundation wall

Fig. 1.2_Backfilling utility cut with CLSM

bases and subgrades. The mixture may be placed directly from the mixer onto the subgrade between 
existing curbs. For base course design under flexible pavements, structural coefficients differ depending upon the strength of the CLSM. Based on structural coefficient values for cement treated bases derived from data obtained in several states, the structural coefficient of a CLSM layer may be estimated to range from 0.16 to 0.28 for compressive strengths from 400 to 1200 psi. $^{3}$

Good drainage, including curb and gutter, storm sewers, and proper pavement grades, is required when using CLSM mixtures in pavement construction. Freezing and thawing damage could result in poor. durability if the base material is frozen when saturated with water.

A wearing surface is required over CLSM since it has relatively poor wear resistance properties. Further infor-mation regarding pavement base materials is found in $\mathrm{ACl} 325$, "Guide for Design of Foundations and Shoul-ders for Concrete Pavements."

\subsection{Conduit bedding}

CLSM provides an excellent bedding material for pipe, electrical, telephone and other types of conduits. The flowable characteristic of the material allows the CLSM to fill voids beneath the conduit and provide a uniform support.

The U.S. Bureau of Reclamation (USBR) began using CLSM in 1964 as a bedding material for 15- to 96-in. diameter concrete pipe along the entire Canadian River Aqueduct Project, which stretches 322 miles from Ama-rillo to Lubbock, Texas. Soil-cement slurry pipe bedding, as referred to by the USBR, was produced in central por-table batching plants which were moved every ten miles along the route. Ready mixed concrete trucks then de-livered the soil-cement slurry to the placement site. The soil was obtained from local blow sand deposits. It was estimated that the soil-cement slurry reduced bedding costs 40 percent. Production increased from 400 linear feet to 1000 linear feet of pipe placed per shift. ${ }^{4}$

CLSM can be designed to provide erosion resistance beneath the conduit. Since the mid 1970s, some county agencies in lowa have been placing culverts on a CLSM bedding. This not only provides a solid, uniform pipe bedding, but prevents water from getting between the pipe and bedding, eroding the support. $^{5}$

Encasing the entire conduit in CLSM also serves to protect the conduit from future damage. If the area around the conduit is being excavated at a later date, the obvious material change in CLSM versus the surrounding soil or conventional granular backfill would be recog-nized by the excavating crew, alerting them to the exis-tence of the conduit. Coloring agents have been used in mixtures to help identify the presence of CLSM.

\subsection{Erosion control}

Laboratory studies as well as field performance have shown that CLSM resists erosion better than many other fill materials. Tests comparing CLSM with various sand and clay fill materials showed that CLSM, when exposed to a water velocity of $1.7 \mathrm{ft} / \mathrm{sec}$, was superior to the other materials, both in the amount of material loss and sus-pended material. ${ }^{11}$

Rip rap for embankment protection and in stilling basins below dam spillways are often filled with CLSM to hold rock pieces in place and prevent erosion. Flexible fabric mattresses used along embankments for erosion protection are filled with CLSM to provide strength and weight to the fabric revetments. In addition to providing an erosion resistance under culverts, CLSM is used to fill voids under pavements, sidewalks, bridges and other structures where natural soil or non-cohesive granular fill has eroded away.

\subsection{Void filling}

2.8.1 Tunnels shafts and sewers In filling old tunnels and sewers it is very important to use a very flowable mixture. A constant supply of CLSM will help keep the material flowing and make it flow greater distances. CLSM was used to fill an abandoned tunnel that passed under the Menomonee River in downtown Milwaukee. The self-leveling material flowed over 235 feet. On another Milwaukee project, 831 yards were used to fill an abandoned sewer. The CLSM reported flowed up to 300 linear feet. ${ }^{6}$

Before constructing the Mount Baker Ridge Tunnel in Seattle, Washington, an exploratory shaft 120 feet deep, 12 feet in diameter with 30 foot-long branch tunnels was excavated. After exploration the shaft had to be filled prior to construction of the tunnel. Only $4 \mathrm{hr}$ were needed to fill the shaft with 786 cubic yards of CLSM. $^{15}$

2.8.2 Basements and underground structures Unwanted basements are often filled-in with CLSM by pumping or conveying the mixture through an open window or door-way. An industrial renovation project in LaSalle, Illinois, required the filling of an existing basement to accommo-date expansion plans. Granular fill was considered, but access problems made CLSM a more attractive alterna-tive. About 400 cubic yards of material were poured in one day. An 8in. concrete floor was placed directly on top of the CLSM mixture.

In Seattle, Washington, buses were to be routed off busy streets into a tunnel with pedestrian stations. The tunnel was built by a conventional method, but the stations had to be excavated from the surface to the station floor. After the station was built there was a 25,000 cubic yard void over each station to the street. So as not to disrupt traffic with construction equipment and materials the voids were filled with CLSM, which required no layered construction or compaction.

CLSM has been used to fill abandoned underground tanks. Federal and State regulations have been 
developed that address closure requirements for underground fuel and chemical tanks. Tanks taken out of service perma-nently must be either removed from the ground or filled with an inert solid material. The lowa Department of Natural Resources guidance document "Underground Storage Tank Closure Procedures for Filling in Place," April, 1992, specifically mentions flowable mortar as a suitable material for tank filling.

\subsection{Nuclear Facilities}

CLSM is used in nuclear facilities for conventional applications such as those described above. It provides a significant advantages over conventional backfill in that remote placement decreases personnel exposure to radiation. CLSM can also be used in unique applications at nuclear facilities for example, waste stabilization, encapsulation of decommissioned pipelines and tanks, encapsulation of waste disposal sites, and new land fill construction. CLSM formulations provide flexibility for designing systems to address a wide range of chemical and radionuclide stabilization requirements.

\section{CHAPTER 3_MATERIALS}

\subsection{General}

Conventional CLSM mixtures usually consist of water, port and cement, fly ash or other similar byproducts, and fine or coarse aggregates or both. Some mixtures consist of water, portland cement and fly ash only. Special low density CLSM (LD-CLSM) mixtures, as described in Chapter 8 of this report, consist of portland cement, water and preformed foam.

Although materials used in CLSM mixtures may meet ASTM or other standard requirements, the use of stan-dardized materials is not always necessary. Selection of materials should be based on availability, cost, specific application and the necessary characteristics of the mix-ture including flowability, strength, excavatability, density, etc.

\subsection{Cement}

Cement provides the cohesion and strength for CLSM mixtures. For most applications, Type I or Type II portland cement conforming to ASTM C 150 is normally used. Other types of cement, including blended cements conforming to ASTM C 595, may be used if prior testing indicates acceptable results.

\subsection{Fly ash}

Materials such as fly ash are sometimes used to improve flowability. Their use may also increase strength and reduce bleeding, shrinkage and permeability. High fly ash content mixtures result in lower density CLSM when compared to mixtures with high aggregate contents. Most fly ashes used conform to either Class $F$ or Class $C$ as described in ASTM C 618. However, fly ashes not con-forming to ASTM C 618 may be used. In all cases, whether or not fly ashes conform to ASTM C 618 speci-fications, trial mixes should be prepared to determine whether the mixture will meet the specified requirements.

\subsection{Chemical admixtures}

Air-entraining admixtures can be valuable constituents for the manufacture of CLSM. Air takes up space and improves flowability, assisting performance while en-hancing economy. It can also be used to enhance insul-ating characteristics and provide for reduced density. It may also be used as a means of limiting the maximum strength of CLSM.

Chemical water-reducing admixtures have been used in CLSM mixtures with low fines content. The purpose is to reduce water content and accelerate hardening while decreasing subsidence.

Caution should be exercised with air contents in excess of 6 percent as they may increase segregation. ${ }^{8}$ However, when the mixture is proportioned with sufficient fines to promote cohesion, air contents as great as 15 to 20 per-cent can be used without adverse segregation.

Although chemical admixtures have been used success-fully in CLSM mixtures, pretesting should be performed to determine acceptability. Also, chemical admixtures may not be cost effective unless they are needed to sat-isfy specific requirements.

\subsection{Other Additives}

Chemical and mineral reagents can be added to CLSM as a replacement for fly ash and/or aggregate to design formulations for special applications. Some example include: Swelling clays, such as bentonite to achieve a low permeability material, zeolites, such as analcime or chabazite to adsorb selected ions; and magnetite or hematite fines for radiation shielding.

\subsection{Water}

$\bar{W}$ ater that is acceptable for concrete mixtures is acceptable for CLSM mixtures. ASTM C 94 on ReadyMixed Concrete provides additional information on water quality requirements.

\subsection{Aggregates}

Aggregates are often the major constituent of a CLSM mixture. The type, grading and shape of aggregates can affect the physical properties such as flowability and compressive strength. Aggregates complying with ASTM C 33 are generally used because concrete producers have these materials in stock.

Granular excavation materials with somewhat lower quality properties than concrete aggregate are a potential source of CLSM materials, and should be considered. However, variations of the physical properties of the mix components will have a significant effect on the mix per-formance. Silty sands 
with up to 20 percent fines (minus \#200 sieve) have proven satisfactory. Also, soils with wide variations in grading have shown to be effective. However, soils with clayey fines have exhibited problems with incomplete mixing, stickiness of the mix, excess water demand, shrinkage, and variable strength. These types of soils are not usually considered for CLSM appli-cations. Aggregates that have been used successfully include: ${ }^{9}$

- ASTM C 33 specification aggregates within speci-fied gradations

- Pea gravel with sand

- $3 / 4$ in. minus aggregate with sand

- Native sandy soils, with more than 10 percent passing a \#200 sieve.

- Quarry waste products, generally _ in. minus aggregates.

\subsection{Non-standard materials}

Non-standard materials, which may be available and more economical, can also be used in CLSM mixtures depending upon project requirements. These materials, however, should be tested prior to use to determine their acceptability in CLSM mixtures.

Examples of non-standard materials that may be suit-able as aggregates for CLSM include bottom ash pro-duced in the coal combustion process, discarded foundry sand, and reclaimed crushed concrete.

Aggregates or mixtures that may swell in service due to expansive reactions or other mechanisms should be avoided. Also, wood chips, wood ash, or other organic materials may not be suitable for CLSM. Fly ashes with carbon contents up to 22 percent have been successfully used for CLSM.

In all cases, the characteristics of the non-standard material should be determined, and the suitability of the material should be tested in a CLSM mixture to deter-mine whether it meets specified requirements. In certain cases, environmental regulations may require prequalifi-cation of the raw material or CLSM mixture or both prior to use.

\subsection{Pond Ash/Basin Ash}

Pond ash, typically a mixture of fly ash and bottom ash slurried into a storage/disposal basin can also be used in CLSM. The proportioning of the pond ash in the resulting mixtures depends on its particle size distribution. Typically it can be substituted for all of the fly ash and a portion of the fine aggregate and water. Unless dried prior to mixing, pond ash requires special mixing since it is usually wet. Basin ash is similar to pond ash except it is not slurried and may be disposed of in dry basins or stockfiles.

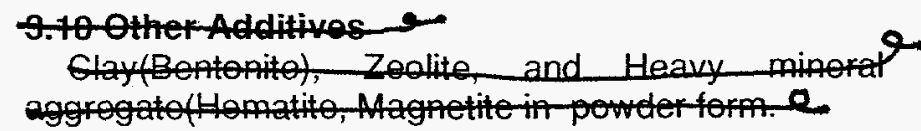

\section{CHAPTER 4 PROPERTIES}

\subsection{Introduction}

The properties of CLSM cross the boundaries between soils and concrete. CLSM is manufactured from materials similar to those used to produce concrete and is placed from equipment in a fashion similar to that of concrete. But in-service CLSM exhibits characteristic properties of soils. The properties of CLSM are affected by the consti-tuents of the mix and the proportions of the ingredients in the mix. Because of the many factors that can affect CLSM, a wide range of values may exist for the various properties discussed below.

\subsection{Plastic properties}

4.2.1 Flowability Flowability is the property that makes CLSM unique as a fill material. It enables the materials to be self-leveling, to flow into and readily fill a void, and be self-compacting without the need for con-ventional placing and compacting equipment. This prop-erty represents a major advantage of CLSM compared to normal fill materials that must be mechanically placed and compacted. Due to its similarity to concrete and grout materials in the plastic state, flowability is best viewed in terms of concrete and grout technology.

A major consideration in using highly flowable CLSM is the hydrostatic pressure it exerts. Where fluid pressure is a concern, CLSM may be placed in lifts, with each lift being allowed to harden before placement of the next lift. Examples where multiple lifts may be required are in the case of limited strength forms that are used to con-tain the material, or where buoyant items such as pipes are encapsulated in the CLSM.

Flowability can be varied from very stiff to very fluid depending upon requirements. Methods of expressing flowability include the use of the standard concrete slump cone (ASTM C 143), flow cone (Corps of Engineers Spec. CRD-C611, or ASTM C 939), and a $3 \times 6$ in. open ended cylinder modified flow test.

Flowability ranges associated with the slump cone can be expressed as follows: ${ }^{10}$

Low flowability minus 6 in.

Normal flowability 6-8 in.

High flowability plus 8 in.

ASTM C 939, for determining flow of grout, has been used successfully with very fluid mixtures containing aggregates not greater than $1 / 4$ in. The method is briefly described in Chapter 7 on Quality Control. The Florida and Indiana Departments of Transportation require an efflux time of 30 seconds \pm 5 seconds as measured by this method.

The modified flow test, also described in Chapter 7 , uses a $3 \times 6$-in. open-ended cylinder and is best adapted to mixtures containing primarily fine 
aggregates. For good flowability, the diameter of spread material should be at least 8 in.

4.2.2 Segregation Separation of constituents in the mixture can occur at very high levels of flowability when the flowability is primarily produced by the addition of water. This situation is similar to segregation experienced with some high slump concrete mixtures. With proper proportioning, a high degree of flowability can be at-tained without segregation.

For highly flowable CLSM without segregation, adequate fines are required to provide suitable cohesiveness. Fly ash generally accounts for these fines, although silty or other noncohesive fines up to 20 percent of total ag-gregate have been used. The use of plastic fines such as clay should be avoided because they can produce deleter-ious results, such as increased shrinkage. In very flowable mixtures, satisfactory performance of CLSM has been ob-tained with Class F fly ash contents as high as $700 \mathrm{lb} / \mathrm{yd}^{3}$ in combination with cement, sand, and water. Some CLSM mixtures have been designed without sand or gravel, using only fly ash as filler material. These mixtures require much higher water content, but produce no noticeable segregation. ${ }^{\text {t1 }}$

4.2.3 Subsidence Subsidence deals with the reduction in volume of CLSM as it releases its water and entrapped air through consolidation of the mixture. Water used for flowability in excess of that needed for consolidation and hydration is generally absorbed by the surrounding soil or released to the surface as bleed water. Most of the subsi-dence occurs during placement and the degree of subsi-dence is dependent upon the quantity of free water re-leased. Typically, subsidence of _to $1 / 4$ in. per foot of depth has been reported. ${ }^{12}$ This amount is generally found with mixtures of high water content. Mixtures of lower water content undergo little or no subsidence and cylinder specimens taken for strength evaluation have experienced no measurable change in height from the time of casting to the time of testing.

4.2.4 Hardening time_Hardening time is the approximate period of time required for CLSM to go from the plastic state to a hardened state with sufficient strength to support the weight of a person. This time is greatly influenced by the amount and rate of bleed water. released. When this excess water leaves the mixture, solid particles realign into intimate contact and the mixture becomes rigid. Hardening time is greatly dependent on the type and quantity of cementitious material in the CLSM.

Normal factors affecting the hardening time are:

- Type and quantity of cementitious material

- Permeability and degree of saturation of surrounding soil which is in contact with CLSM

- Fluidity of CLSM

- Proportioning of CLSM

- Mixture and ambient temperature

- Humidity
- Depth of fill

Hardening time can be as short as one hour, but gen-erally takes 3 to 5 hours under normal conditions. ${ }^{1,8,12}$ A penetration resistance test according to ASTM C 403 can be used to measure the hardening time or approximate bearing capacity of CLSM. Depending upon the applica-tion, penetration numbers of 500 to 1500 are normally required to assure adequate bearing capacity. ${ }^{13}$ As an example, the California Department of Transportation requires a penetration number of 650 before allowing a pavement surface to be placed.

4.2.5 Pumping CLSM can be successfully delivered by conventional concrete pumping equipment. As with con-crete, proportioning of the mixture is critical. Voids must be adequately filled with solid particles to provide ade-quate cohesiveness for transport through the pump line under pressure without segregation. Inadequate void fill-ing results in mixtures that may segregate in the pump and may cause line blockage. Also, it is important to maintain a continuous flow through the pump line. Inter-rupted flow may cause segregation which restricts flow and could result in line blockage.

In one example, CLSM using unwashed aggregate with a high fines content was pumped through a 5 in. pump system at a rate of 60 cubic yards per hour. ${ }^{14}$ In another example, CLSM with a slump as low as 2 in. has been successfully delivered by concrete pump without the need for added consolidation effort. ${ }^{15}$

CLSM with high entrained air contents can be pumped, although care should be taken to keep pump pressures low. Increased pump pressures may cause a loss in air content and reduce pumpability.

Pumpability can be enhanced by careful proportioning to provide adequate void filling in the mixture. Fly ash can aid pumpability by acting as microaggregate for void filling. Cement can also be added, for this purpose. How-ever, whenever cementitious materials are added care must be taken to limit the maximum strength levels if later excavation is a consideration.

\subsection{In-service properties}

4.3.1 Strength (bearing capacity) Unconfined compres-sive strength is a measure of the load carrying ability of CLSM. A CLSM compressive strength of 50 to 100 psi equates to an allowable bearing capacity of a well com-pacted soil. Curing methods specified for concrete are not considered essential for CLSM. ${ }^{9}$

Maintaining strengths at a low level is a major objective for projects where later excavation may be required. Some mixtures that are acceptable at early ages continue to gain strength with time, making future exca-vation difficult. Section 4.3.7 provides additional infor-mation on excavatability. 
4.3.2 Density Density of normal CLSM in place is in the range of $11 \overline{5}-145 \mathrm{lb} / \mathrm{ft}^{3}$, which is greater than most compacted materials. A CLSM mix with only fly ash, ce-ment and water should have a density between 90 to $100 \mathrm{lb} / \mathrm{ft}^{3}$. . Lower unit weights can be achieved by using light-weight aggregates, high entrained air contents, and foam-ed mixes, which are discussed in detail in Chapter 8.

4.3.3 Dry Density of normal CLSM in the range of $110-118 \mathrm{lbs} / \mathrm{ft}^{3}$. Pond ash/basin ash CLSM mix is in the range of $85-110 \mathrm{lbs} / \mathrm{ft}^{3}$

4.3.4 Settlement Settlement of compacted fills may occur even when compaction requirements have been met. CLSM does not settle after hardening occurs. Measurements taken months after placement of a large CLSM fill showed no measurable deformation. ${ }^{16}$ For a project in Seattle, Washington, $786 \mathrm{yd}^{3}$ were used to fill a $120 \mathrm{ft}$ deep shaft. The placement took four hours and the total settlement was reported to be about _ in. ${ }^{15}$

4.3.5 Thermal insulation/conductivity Conventional CLSM mixtures are not considered good insulating materials. Where insulation is desired, the mixture should be proportioned to obtain low density and high porosity. Air entrained conventional mixtures reduce the density and increase the insulating value. Lightweight aggregates, including bottom ash, can be utilized to reduce density. Foamed or cellular mixtures have very low densities and exhibit good insulating properties.

Where high thermal conductivity is desired, such as backfill for underground power cables, high density and very low porosity (maximum surface contact area be-tween solid particles) are desirable. As the moisture content and dry density increase, so does the thermal conductivity. Other parameters to consider, but of lesser importance, include mineral composition, particle shape and size, gradation characteristics, organic content and specific gravity. ${ }^{17-19}$

4.3.6 Permeability_Permeability of most excavatable CLSM is similar to compacted granular fills. Typical val-ues are in the range of $10^{-4}$ to $10^{-5}$ $\mathrm{cm} / \mathrm{sec}$. Mixtures of higher strength and higher fines content of CLSM can achieve permeabilities as low as $10^{-7} \mathrm{~cm} / \mathrm{sec}$. Permeability is increased as cementitious materials are reduced and aggregate contents are increased (particularly above 80 percent). ${ }^{12}$ Materials normally used for reducing per-meability, such as bentonite clay and diatomaceous earth, may affect other properties, however, and should be tested prior to use.

4.3.7 Shrinkage (cracking) Shrinkage and shrinkage cracks do not affect the performance of CLSM. Several reports have indicated very little shrinkage occurs with CLSM. Typical linear shrinkage is in the range of 0.02 to 0.05 percent. ${ }^{6,9,12}$

4.3.8 Excavatability The ability to excavate CLSM at later ages is an important consideration on many pro-jects. In general, CLSM with a compressive strength of 50 psi or less may be excavated manually. Mechanical equipment such as backhoes are used for compressive strengths of 100 to 200 psi (Fig. 4.1). The limits for excavatability are somewhat arbitrary depending upon the CLSM mixture. Mixtures using high quantities of coarse aggregate can be very difficult to remove by hand even at low strengths. Mixtures using fine sand or only fly ash as

\section{Fig. 4.1_Excavating CLSM with backhoe}

the aggregate filler may be excavated with a backhoe at strengths of 300 psi. $^{11}$

Where later age excavatability is of concern, the type and quantity of cementitious materials is important. Ac-ceptable long term performance has been achieved with cement contents from 40 to 100 $\mathrm{lb} / \mathrm{yd}^{3}$ and Class F fly ash contents up to $350 \mathrm{lb} / \mathrm{yd}^{3}$. Lime $(\mathrm{CaO})$ contents of fly ash that exceed 10 percent by weight may be a concern where long term strength increases are not desired. $^{9}$

Since CLSM will typically continue to gain strength beyond the conventional 28-day testing period, it is sug-gested, especially for high cementitious content CLSM, that long term strength tests be conducted to estimate the potential for later age excavatability.

In addition to limiting the cementitious content, entrained air can be used to keep compressive strengths low

4.3.9 Shear Modulus of normal CLSM in the range of $3.4-3.6 \mathrm{Ksf}$.

\section{CHAPTER 5_MIX PROPORTIONING}

Proportioning for CLSM has largely been done by trial and error until mixtures with suitable properties have been achieved. Most specifications available provide a recipe of ingredients that will produce an acceptable material, although some specifications call for perfor-mance features and leave proportioning up to the sup-plier. "Selecting Proportions for Normal, 
Heavyweight and Mass Concrete" $(\mathrm{ACl} 211)^{11}$ has been used; however, much work remains to be done in establishing consistent reliability when using this method. ${ }^{15}$

Currently, where a recipe does not exist, trial mixtures are evaluated to determine how well they meet certain goals for strength, flowability, density, etc. Adjustments are then made to achieve the desired properties.

Table 5.1 presents a number of mix designs that have been used; however, materials and project requirements may differ considerably. What works in one part of the country or from one supplier may be inappropriate else-where. Therefore, information in Table 5.1 is provided as a guide and should not be used for design purposes without first testing with locally available materials.

The following summary can be made regarding the materials used to manufacture CLSM:

- Cement Cement contents generally range from 50 to $2 \overline{0} 0 \mathrm{lb} / \mathrm{yd}^{3}$, depending upon strength and hard-ening time requirements. Increasing cement content while maintaining all other factors equal, that is, water, fly ash, aggregate and ambient temperature will normally increase strength and reduce hard-ening time.

- Fly ash_Class F fly ash contents range from none to as high as $2000 \mathrm{lb} / \mathrm{yd}^{3}$ where fly ash serves as the aggregate filler. Class $\mathrm{C}$ fly ash is used in quantities of up to $350 \mathrm{lb} / \mathrm{yd}^{3}$. The quantity of fly ash used will be determined by availability and flowability needs of the project.

Pond ash/Basin ash contents range from 500 to $950 \mathrm{lbs} / \mathrm{yd}^{3}$, depending upon the fineness of ash.

- Aggregate The majority of specifications call for the use of fine aggregate. The amount of fine aggregate varies with the quantity needed to fill the volume of the CLSM after considering cement, fly ash, water, and air contents. In general, the quan-tities range from 2600 to $3100 \mathrm{lb} / \mathrm{yd}^{3}$. Coarse aggre-gate is generally not use in CLSM mixes as often as fine aggregates. When used, however, the coarse aggregate content is approximately equal to the fine aggregate content.

- Water More water is used in CLSM than in concrete. Water serves as a lubricant to provide high flowability characteristics and promote consolidation of the materials. Water contents typically range from 325 to $580 \mathrm{lb} / \mathrm{yd}^{3}$ for most CLSM mixes con-taining aggregate. Water content for Class F fly ash and cement only mixes can be as high as $1000 \mathrm{lb} / \mathrm{yd}^{3}$ to achieve good flowability. This wide range is due primarily to the characteristics of the mater-ials used in CLSM and the degree of flowability desired. Water contents will be higher with mix-tures using finer aggregates.
Other additives such as zeolites, heavy minerals, and clays can be added to typical clsm mixes in the range of 2 to 10 percent. Fly ash and cement may be adjusted accordingly while maintaining all other factors equal.

\section{CHAPTER 6 MIXING, TRANSPORTING, AND PLACING}

\subsection{General}

The mixing, transporting and placing of CLSM gener-ally follows methods and procedures given in $\mathrm{ACl} 304$. However, other methods may be acceptable if prior ex-perience and performance data are available. Whatever methods and procedures are used, the main criteria is that the CLSM be homogeneous and consistent and satis-fy "the requirements for the purpose intended.

\subsection{Mixing}

$\bar{C}$ LSM may be mixed by several methods, including central-mixed concrete plants, ready-mixed concrete trucks, and pugmills. For high fly ash mixtures, where fly ash is delivered to the mixer from existing silos, batching 
TABIE 5.1 Examples of CLSM mixture designs*

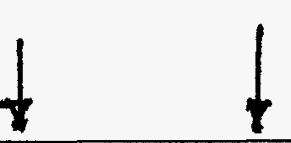

\begin{tabular}{|c|c|c|c|c|c|c|c|c|c|c|c|c|c|c|c|c|c|c|c|c|c|}
\hline \multirow{2}{*}{ Source } & \multirow{2}{*}{$\begin{array}{l}\text { CO } \\
\text { DOT }\end{array}$} & \multirow{2}{*}{$\begin{array}{l}\text { IA } \\
\text { DOT }\end{array}$} & \multirow{2}{*}{$\begin{array}{c}F L \\
\text { DOT }\end{array}$} & \multirow{2}{*}{$\begin{array}{l}\text { IL } \\
\text { DOT }\end{array}$} & \multicolumn{2}{|c|}{ IN DOT } & \multirow{2}{*}{$\begin{array}{c}\text { OK } \\
\text { DOT }\end{array}$} & \multicolumn{2}{|c|}{ MIDOT } & \multicolumn{2}{|c|}{ OH DOT } & \multirow{2}{*}{$\begin{array}{l}\text { SC } \\
\text { DOT }\end{array}$} & \multirow{2}{*}{$\begin{array}{l}\text { DOE- } \\
\mathrm{SR}^{18}\end{array}$} & \multirow{2}{*}{$\mid \begin{array}{cc} & \text { Unb } \\
\text { rink } & - \\
\text { able } & \text { fill }\end{array}$} & \multicolumn{2}{|c|}{$\begin{array}{l}\text { Pond ash } \\
\text { /basin } \\
\text { ash mix }{ }^{19}\end{array}$} & \multicolumn{2}{|c|}{$\begin{array}{l}\text { Coarse } \\
\text { aggregate } \\
\text { CLSM }^{10}\end{array}$} & \multicolumn{3}{|c|}{$\begin{array}{l}\text { Flowable fly ash } \\
\text { slurry }\end{array}$} \\
\hline & & & & & Mix 1 & $\operatorname{Mix} 2^{6}$ & & Mix 1 & Mix 2 & Mix 1 & Mix 2 & & & & $\begin{array}{l}\text { Mix } \\
\text { AF }\end{array}$ & Mix D & $\begin{array}{l}\text { Non-ain } \\
\text { entrain- } \\
\text { ment }^{15}\end{array}$ & $\begin{array}{c}\text { Air en } \\
\text { train- } \\
\text { ment }\end{array}$ & $\underset{\mathrm{Six}}{\operatorname{Mix}}$ & $\underset{S-3^{16}}{\operatorname{Mix}}$ & $\begin{array}{c}\operatorname{Mix} \\
S-4^{17}\end{array}$ \\
\hline $\begin{array}{l}\text { Cement } \\
\text { Content }\end{array}$ & 50 & 100 & $\begin{array}{c}50- \\
100^{3} \\
\end{array}$ & 50 & 60 & 185 & $50 \mathrm{~min}$ & 100 & 50 & 100 & 50 & 50 & 50 & 60 & $\begin{array}{ll}165 \\
\end{array}$ & 100 & 50 & 50 & 98 & 158 & 144 \\
\hline $\begin{array}{l}\text { Fly ash } \\
\left(\mathrm{lb} / \mathrm{y} d^{3}\right)\end{array}$ & - & 300 & $0-600^{4}$ & $\begin{array}{c}300 \\
\text { Class F } \\
\text { or } 200 \\
\text { Class C }\end{array}$ & $\overline{330}$ & - & 250 & $\begin{array}{c}2000 \\
\text { Class F }\end{array}$ & \begin{tabular}{c|}
550 \\
Class F
\end{tabular} & 250 & 250 & 600 & $\begin{array}{c}600 \\
\text { Class } F\end{array}$ & - & $810^{120}$ & $550^{21}$ & 250 & 250 & \begin{tabular}{|l|}
1366 \\
Class \\
$F$
\end{tabular} & \begin{tabular}{|l|}
1262 \\
Class \\
F
\end{tabular} & \begin{tabular}{|l|}
1155 \\
Class \\
$F$
\end{tabular} \\
\hline \begin{tabular}{l|} 
Coars \\
aggregate \\
$\left(\mathrm{lb} / \mathrm{yd}^{3}\right)$
\end{tabular} & $1700^{\circ}$ & - & - & - & - & - & - & - & \begin{tabular}{c|} 
Foot- \\
note $\# 7$
\end{tabular} & -- & - & - & . & \begin{tabular}{|l|}
$1705(3 / 4-$ \\
in. $\max )$
\end{tabular} & 2190 & 2515 & $\begin{array}{l}1900(1 \\
\text { in. } \max \\
\end{array}$ & $\begin{array}{l}1900 \\
(1 \\
\text { in. } \\
\max )\end{array}$ & - & - & - \\
\hline $\begin{array}{l}\text { Fine } \\
\text { aggregate } \\
\left(\mathrm{lb} / \mathrm{yd}^{3}\right)\end{array}$ & $1842^{2}$ & 2600 & $2750^{5}$ & 2900 & 2860 & 2675 & 2910 & .. & \begin{tabular}{c|} 
Foot- \\
note $\# 7$
\end{tabular} & 2850 & 2910 & 2500 & 2515 & 1977 & & & 1454 & 1340 & - & .- & .. \\
\hline $\begin{array}{l}\text { Approxi- } \\
\text { mate } \\
\text { water } \\
\text { content } \\
\left(\mathrm{Ib} / y \mathrm{~d}^{3}\right)\end{array}$ & 325 & 585 & $\begin{array}{l}500 \\
\max \end{array}$ & $375-540$ & 510 & 500 & $\begin{array}{l}500 \\
\max \end{array}$ & 665 & 330 & 500 & 500 & $\begin{array}{l}460- \\
540\end{array}$ & $\begin{array}{c}500- \\
550\end{array}$ & $257^{8}$ & 700 & 507 & $270^{12}$ & $255^{12}$ & 1068 & 1052 & 1146 \\
\hline $\begin{array}{l}\text { Comp. } \\
\text { strength at } \\
28 \text { days } \\
\text { (psi) }\end{array}$ & 60 & - & $50-150$ & - & - & - & - & - & - & - & - & 80 & $30-150$ & $\begin{array}{l}17 \text { @ } \\
1 \text { day }\end{array}$ & 65 & 65 & 100 & - & $\begin{array}{c}40 \\
(40 @ \\
56 \\
\text { days }) \\
\end{array}$ & \begin{tabular}{|c|}
60 \\
$(750$ \\
56 \\
days $)$ \\
\end{tabular} & \begin{tabular}{|c|}
50 \\
$(70 @ 9$ \\
56 \\
days $)$
\end{tabular} \\
\hline
\end{tabular}

-Table examples are based on experience and test results using local materials. Yields will vary from 27 cubic feet. This table is given as a guide and should not be used for design purposes without first testing

with locally available materials.

ASTMC 33, No.

(a)

"Granulated blast-fumace slag may be used in place of thy ash.

${ }^{5}$ Adjust to yield one cubic yard of CLSM.

"Fve to six thild cunces of air entraining admixture produces 7 to 12 percent air contents.

$2850 \mathrm{lby} \mathrm{d}^{3}$ with $3 / \mathrm{in}$. maximum size aggregate.

OProduces 6 in. slumin.

${ }_{11}^{10}$ Reference 15

12 produces approximately 1.5 percent air conten

13 Produces 5 percent slump.

(1) Peterence 6 .

19. Produces a modified flow of 8/4 in. dia. (see Tabla 7.1); air content of 0.8 percent; slurry density of $93.7 \mathrm{lb} / \mathrm{th}$.

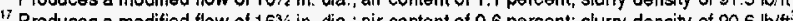

18. DOE Savannah River Site CLSM mix

19 DOE Savannah River Site CLSM mix using pond/basin ash

20 Basin ash mix

21 Pond ash mix 
operations may be slow.

Truck mixers are commonly used by ready mixed concrete producers to mix CLSM; however, in-plant central mixers can be used as well. In truck mixing operations, the following is one procedure that can be used for charging truck mixers with batch materials.

Load truck mixer at standard charging speed in the following sequence:

(Step 1) Add 70 percent to 80 percent of water required.

(Step 2) Add 50 percent of the aggregate filler.

(Step 3) Add all cement and fly ash required.

(Step 4) Add balance of aggregate filler.

(Step 5) Add balance of water.

For CLSM mixtures consisting of fly ash, cement, water, and no aggregate filler, an effective mixing method consists of initially charging the truck mixer with cement then water. After thoroughly mixing these materials, the fly ash is added. Additional mixing for a minimum of 15 minutes was required in one case to produce a homogen-eous slurry.

Pugmill mixing works efficiently for both high and low fly ash mixtures and other high fines content mixtures. For high fly ash mixtures the fly ash is fed into a hopper with a front-end loader, which supplies a belt conveyor under the hopper. This method of feeding the mixer is much faster than silo feed. To prevent bridging within the fly ash, a mechanical agitator or vibrator is used in the hopper. Cement is usually added from silo storage onto the conveyor prior to entering the mixer. If bag cement is used, it is added directly into the mixer. The measurement for payment of CLSM mixed through a pugmill is generally based on weight rather than volume, which is typically used for concrete.

\subsection{Transporting}

Most CLSM mixtures are transported in truck mixers. Agitation of CLSM is required during transportation and waiting time to keep the material in suspension. Under certain circumstances CLSM has been transported short distances in non-agitating equipment such as dump trucks. Agitator trucks, although providing some mixing action may not provide enough to prevent the solid materials from settling-out.

CLSM has been transported effectively by pumps and conveyor belts. In pumping CLSM, the fly ash serves as a lubricant to reduce the friction in the pipeline. The fine texture of the fly ash, however, requires the pump be in excellent condition and properly cleaned and maintained.

\subsection{Placing}

CLSM may be placed by chutes, conveyors, buckets, or pumps depending upon the application and its accessibil-ity. Internal vibration or compaction is not required since the CLSM consolidates under its own weight. Although it can be placed year round, CLSM should be protected from freezing until it has hardened.

For trench backfill, CLSM is usually placed continuously. To contain CLSM when filling long open trenches in stages or open-ended structures such as tunnels, the end points can be bulkheaded with sandbags, earth dams, or stiffer mixtures of CLSM.

For pipe bedding, CLSM may have to be placed in lifts to prevent floating the pipe. Each lift should be allowed to harden before continued placement. Other methods of preventing floatation include sand bags placed over the pipe, straps around the pipe anchored into the soil or use of faster setting CLSM placed at strategic locations over the pipe.

CLSM is not self-supporting and places a load on the pipe. For large, flexible wall pipes, CLSM should be placed in lifts so that lateral support can develop along the side of the pipe before fresh CLSM is placed over the pipe. Backfilling retaining walls may also require the CLSM be placed in lifts in order to prevent overstressing the wall.

CLSM has effectively been tremied and end dumped directly into the water ${ }^{11}$ without significant segregation. In confined areas the CLSM will displace the water to the surface where it can easily be removed. Because of its very fluid consistency, CLSM can flow long distances to fill voids and cavities located in hard-to-reach places. Voids need not be cleaned as the slumy will fill in irregularities and encapsulate any loose materials.

\section{CHAPTER 7 QUALITY CONTROL}

\subsection{General}

The extent of a quality control (QC) program for CLSM can vary depending upon previous experience, ap-plication, raw materials used and level of quality desired. A QC program may be as simple as a visual check of the completed work where standard, pretested mixtures are being used. Where the application is critical, the mater-ials nonstandard, or where product uniformity may be questionable, regular tests for consistency and strength may be appropriate.

Both as-mixed and in-service properties can be measured to evaluate the mixture consistency and performance. For most projects CLSM is pretested using the actual raw materials to develop a mix design having certain plastic (flowability, consistency, unit weight) and hardened (strength, durability, permeability) characteristics. Following the initial testing program, field testing may consist of simple visual checks, or it may include consistency measurements or compressive strength tests.

As stated, above the QC program can be simple or detailed. It is the responsibility of the specifier to determine an appropriate QC program which will assure that the product will be adequate for its intended use. The following procedures and test methods have been used to evaluate CLSM mixtures.

\subsection{Consistency and unit weight}

Depending upon application and placement requirements, flow characteristics can be important. CLSM consistency can vary considerably from plastic to fluid; therefore, several methods of measurement are available. Most CLSM mixtures perform well under 
varied flow and unit weight conditions. Table 7.1 describes methods that can be used to measure consistency and unit weight.

\subsection{Strength tests}

$\bar{C} L S M$ is used in a variety of applications requiring different load-carrying characteristics. The maximum loads to be imposed on the CLSM should be identified as a means of determining the minimum strength requirements. In many cases, however, CLSM needs to be limited in its maximum strength. This is especially true where removal of the material at a later date is anticipated.

The strength of CLSM can be measured by several methods. Unconfined compressive strength tests are the most common; however, other methods such as penetro-meter devices or plate load tests can also be used. Compressive strength specimens can vary in size from $2 \times 2$ in. cubes to $6 \times 12$ in. cylinders. Special care may be needed in removing very low strength CLSM mixtures from test molds. Some ASTM test methods used to determine strength of CLSM are given in Table 7.2.

\section{CHAPTER 8 LOW DENSITY CLSM USING PREFORMED FOAM}

\subsection{General}

This chapter is limited to low density CLSM mixtures (LD-CLSM) made with preformed foam. Low density CLSM mixtures are primarily used where a lightweight fill is required Because ID-CLSM requires different materials and mixing and placing equipment than those associated with conventional CLSM, a separate chapter on LD-CLSM is provided.

\subsection{Applications}

Low density CLSM mixtures can be used anywhere conventional CLSM mixtures are considered. The low unit weight is especially advantageous where weak soil conditions are encountered and the weight of the fill must be minimized. LD-CLSM is also effective as an in-

Table 7.1 - Test procedures for determining consistency and unit weight of CLSM mixtures

Consistency

Fluid mixtures

- ASTM C 939 "Flow of Grout for Preplaced-Aggregate Concrete." Florida Department of Transportation and Indiana Department of Transportation specifications require an efflux time of 30 seconds \pm 5 seconds. This procedure is not recommended for CLSM mixtures con-taining aggregates greater than $3 / 4$ in.

- Modified flowthe procedure consists of placing a 3 in. diameter $\times 6$ in. long open ended cylinder vertically on a level surface and filing the cylinder to the top with CLSM. The cylinder is then lifted vertically, to allow the material to fiow out onto the level surface. Good flowability is achieved where there is no noticeable segregation and the material spread is at least 8 in. diameter.

- Corp of Engineers,

CRD-C611 "Method of Test for Flow of Grout Mixtures." lowa Department of Transportation specification for flowable mortar requires a target efflux time of about 12 seconds. Flow is based on the material passing a $1 / 4$ in. screen.

Plastic mixtures

- ASTM C 143 "Slump of Portland Cement Concrete."

Unit weight

- ASTM C 138 Unit Weight, Yield and Air Content (Gravimetric) of Concrete."

- ASTM D 4380"Density of Bentonitic Sluries." Not recommended for CLSM containing aggregate greater than $\mathrm{x}$ in.

- ASTM C 1152. "Acid-Soluble Chloride in Mortar and Concrete."

Table 7.2 Test procedures for determining strength CLSM mixtures

- ASTM C 403 Time of Setting of Concrete Mixtures by Penetration Resistance "This test measures the degree of hardness of CLSM. California Department of Transportation requires a penetration number of 650 before allowing a pavement surface to be placed.

- ASTM D 4832"Preparation and Testing of Soli-Cement Slurry Test Cylinders." This test is used for molding cylinders and determining the compressive strength of hardened CLSM.

- ASTM D 1196"Nonrepetitive Static Plate Load Tests of Soils and Flexible Pavement Components for Use in Evalua tion and Design of Airport and Highway Pavements." This test is used to determine modulus of subgrade reaction (K values).

- ASTM D 4429"Bearing Ratio of Solis in Place." This test is used to determine the relative strength of the CLSM in place.

sulating and isolation fill. The air cell structure inherent in LD-CLSM mixtures provides thermal insulation and shock mitigation properties to the fill material.

\subsection{Materials}

The basic materials for most LD-CLSM mixes are portland cement, water, and preformed foam. Other materials such as fly ash may be used to produce LDCLSM; however, mixtures should be pretested prior to use.

Preformed foam is the main ingredient in LD-CLSM mixtures. The foam is produced by first diluting the foam concentrate with water, combining that mixture with compressed air, and passing it through a blending device or foam generator. This expands the mixture volume up to 20 times, forming a micro-bubbled, stable foam.

Foam concentrate must have a chemical composition capable of producing stable air cells that resist the physical and chemical forces imposed during the mixing, placing, and setting of the LD-CLSM mixture. If the cellular structure is not stable, a non-uniform increase in density will result. Procedures for evaluating foam concentrates are specified in ASTM C 796 and ASTM C 869. Further information on this material can be found 
in ACl 523, "Guide for Cast-in-Place Low Density Concrete."

\subsection{Properties}

The properties of LD-CLSM are density related. If standard materials are used, the LD-CLSM has properties that fall within ranges described by the manufacturer of the foam concentrate. If non-standard materials are used, special test batches may be required to confirm certain properties.

The most significant property of LD-CLSM is the inservice density. Table 8.1 divides the in-service density into convenient ranges relating density with typical minimum compressive strength values. Classes $\mathrm{VI}$ and $\mathrm{VII}$ may be subdivided into smaller ranges for specific applications.

\subsection{Proportioning}

The manufacturer of the foam concentrate is generally responsible for the mix design, which is based on desired physical properties (density, compressive strength, etc.) of the in-place material.

\subsection{Construction}

8.6.1 Batching Materials for LD-CLSM are typically proportioned and batched on-site directly into a specialized mixer. Portland cement, fly ash, and aggregates are individually weighed before entering the mixer. Water is then metered into the mixture. The preformed foam is then injected into the mixture through a calibrated nozzle. The accuracy of each batching device is critical to the final mixture density and its subsequent reproducibility.

8.6.2 Mixing_Mixers for LD-CLSM are different from standard CLSM mixers. Normal truck mixers are not recommended for LD-CLSM because the action of the mixer does not properly combine the ingredients with sufficient mixing action and speed. Mixers that provide vigorous mixing action such as high speed paddle mixers are preferred. Other mixers and processes that produce uniformly consistent mixtures are also acceptable.

Table 8.1_Typical strength properties of low density CLSM based on density

8.6.3 Placing_LD-CLSM is typically pumped through a hose to the placement area. Although the material is batched and mixed on-site, the equipment is not sitemobile. LD-CLSM can be pumped over $1000 \mathrm{ft}$. This is important on congested or remote projects with difficult access.

$$
\begin{aligned}
& \text { Conversion Factors } \\
& 1 \mathrm{ft}=0.305 \mathrm{~m} \\
& 1 \text { in. }=25.4 \mathrm{~mm} \\
& 1 \mathrm{lb}=0.454 \mathrm{~kg} \\
& 1 \mathrm{yd}^{3}=0.7646 \mathrm{~m}^{3} \\
& 1 \mathrm{psi}=6.895 \mathrm{kPa} \\
& 1 \mathrm{lb} / \mathrm{ft}^{3}=16.02 \mathrm{~kg} / \mathrm{m}^{3} \\
& 1 \mathrm{lb} / \mathrm{yd}^{3}=0.5933 \mathrm{~kg} / \mathrm{m}^{3} \\
& 1 \mathrm{ft} / \mathrm{sec}=\quad 30.5 \mathrm{~cm} / \mathrm{sec}
\end{aligned}
$$

\section{CHAPTER 9_REFERENCES}

\section{1_Specified references}

\section{American Concrete Institute}

211 Selecting Proportions for Normal, Heavyweight and Mass Concrete

304 Guide for Measuring, Mixing, Transporting and Placing Concrete

325 Guide for Design of Foundations and Shoulders for Concrete Pavements

523 Guide for Cast-in-Place Low Density Concrete

\section{ASTM}

C 33 Standard Specification for Concrete Aggregates

C 94 Standard Specifications for Ready-Mixed Concrete

C 138 Standard Test Method for Unit Weight, Yield and Air. Content (Gravimetric) of Concrete

C 143 Standard Test Method for Slump of Hydraulic Cement Concrete

C 150 Standard Specification for Portland

Cement

C 403 Standard Test Method for Time of Setting of Concrete Mixtures by Penetration Resistance

C595 Standard Specification for Blended Hydraulic Cements

C 618 Standard Specification for Fly Ash and Raw or Calcíned Natural Pozzolan for Use as a Mineral Admixture in Portland Cement Concrete

C796 Standard Test Method of Testing Foaming Agents for Use in Producing Cellular Concrete Using Preformed Foam

C 869 Standard Specification for Foaming Agents Used in Making Preformed Foam for Cellular Con-crete

C 939 Standard Test Method for Flow of Grout for Preplaced-Aggregate Concrete

D 1196 Standard Test Methods for Nonrepetitive Static Plate Load Tests of Soils and 
Flexible Pavement Components for Use in Evaluation and Design of Airport and Highway Pavements

D 4380 Standard Test Method for Density of Bentonitic Slurries

D 4429 Standard Test Method for Bearing Ratio of Soils in Place

D 4832 - Standard Test Method for Preparation and Test-ing of Soil-Cement Slurry Test Cylinders

\subsection{Cited references}

Smith, A., "Controlled Low-Strength Material," Con-crete Construction, May 1991.

2.

Larsen, R.L., "Use of Controlled Low-Strength Materials in lowa," Concrete Intemational, July 1988.

3.

"AASHTO Guide for Design of Pavement Struc-tures," American Association of State Highway and Transportation Officials, Washington, D.C., 1986.

4.

Lowitz, C.A., and Defroot, G., "Soil-Cement Pipe Bedding, Canadian River Aqueduct," Joumal of the Construction Division, ASCE, Vol. 94, No. C01, January 1968.

5.

Larsen, R.L., "Sound Uses of CLSM in the Environment," Concrete International, July 1990.

6.

Naik, T.R., Ramme, B.W., and Kolbeck, H.J., "Filling Abandoned Underground Facilities with CLSM Fy Ash Slurry," Concrete International, July 1990.

7.

Illinois Ready Mixed Concrete Association News-letter, "Flowable Fill," July 1991.

8.

"Unshrinkable Fill for Utility Trenches in Streets," Canadian Portland Cement Association, CP004, 1990.

9.

Tansley, R., and Bemard, R., "Specification for Lean Mix Backfill," U.S. Department of Housing and Urban Development, Contract \#H-5208, October 1981.

10.

"Suggested Specifications for Controlled Density Fill," Washington Aggregates and Concrete Association, Seattle, Washington.

11.

Krell, W.C., "Flowable Fly Ash," Concrete Intema-tional, November 1989.

McLaren, R.J., and Balsamo, N.J., "Fly Ash Design Manual for Road and Site Applications; Volume 2: Slurried Placement," Electric Power Research Institute, Research Report No. CS-4419, October 1986.

13.

"What, Why and How? Flowable Fill Materials," National Ready Mixed Concrete Association, CIP17, 1989.

14.

"Soil-Cement Pumped for Unique Siphon Project," Rocky Mountain Construction, February 17, 1986.
15.

Fox, T.A., "Use of Coarse Aggregate in Controlled Low Strength Materials," Transportation Research Board 1234, 1989.

16.

Flechsig, J.L., "Downtown Seattle Transit Project," International Symposium on Unique Underground Structures, Denver, CO, June 1990.

17.

Steinmanis, J.E., "Underground Cable Thermal Backfill,"

Proceedings of the Symposium on Underground Cable

Thermal Backfill, Toronto, Canada, September 1981.

Parmar, D., "Current Practices for Underground Cable Thermal Backfill," UTTF Meeting, Montreal, Canada, September 1991.

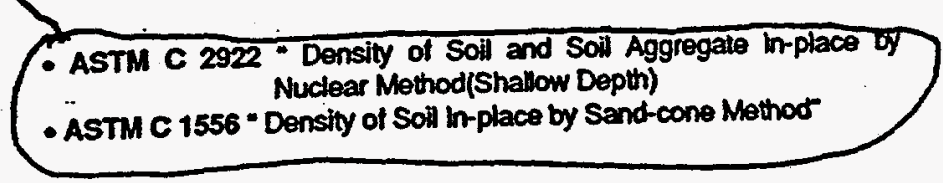


19.

Parmar, D., "Optimizing the Use of Controlled Backfill to Achieve High Ampacities on Transmission Cable," Proceedings of Power Engineering Society Insulated Conductors Committee, 1992.

20.

Glogowski, P.E., and Kelly, J.M., "Laboratory Testing of Fly Ash Slurry," Electric Power Research Institute, EPRI CS-6100, Project 2422-2, December 1988.

\section{1.}

Emery, J. and Johnston, T., "Unshrinkable Fill for Utility Cut Restorations," American Concrete Institute, Special Publication 93-10, 1986.

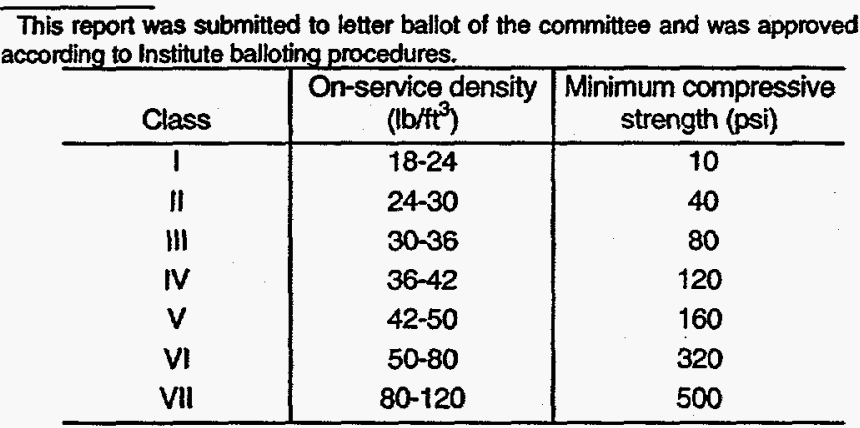

